\title{
Influence of the Eurasian snow on the negative North Atlantic Oscillation in subseasonal forecasts of the cold winter 2009/2010
}

\author{
Y. J. Orsolini ${ }^{1,2} \cdot$ R. Senan ${ }^{3} \cdot$ F. Vitart ${ }^{4} \cdot$ G. Balsamo $^{4} \cdot$ A. Weisheimer ${ }^{4} \cdot$ \\ F. J. Doblas-Reyes ${ }^{5}$
}

Received: 26 February 2015 / Accepted: 30 October 2015 / Published online: 20 November 2015

(c) The Author(s) 2015. This article is published with open access at Springerlink.com

\begin{abstract}
The winter 2009/2010 was remarkably cold and snowy over North America and across Eurasia, from Europe to the Far East, coinciding with a pronounced negative phase of the North Atlantic Oscillation (NAO). While previous studies have investigated the origin and persistence of this anomalously negative NAO phase, we have re-assessed the role that the Eurasian snowpack could have played in contributing to its maintenance. Many observational and model studies have indicated that the autumn Eurasian snow cover influences circulation patterns over high northern latitudes. To investigate that role, we have performed a suite of forecasts with the coupled oceanatmosphere ensemble prediction system from the European Centre for Medium-Range Weather Forecasts. Pairs of 2-month ensemble forecasts with either realistic or else randomized snow initial conditions are used to demonstrate how an anomalously thick snowpack leads to an initial cooling over the continental land masses of Eurasia and, within 2 weeks, to the anomalies that are characteristic of
\end{abstract}

Electronic supplementary material The online version of this article (doi:10.1007/s00382-015-2903-8) contains supplementary material, which is available to authorized users.

Y. J. Orsolini

orsolini@nilu.no

1 NILU - Norwegian Institute for Air Research, Kjeller, Norway

2 Bjerknes Centre for Climate Research, University of Bergen, Bergen, Norway

3 Department of Geosciences, University of Oslo, Oslo, Norway

4 ECMWF, Reading, England, UK

5 Institució Catalana de Recerca i Estudis Avançats - ICREA, Barcelona, Spain a negative NAO. It is also associated with enhanced vertical wave propagation into the stratosphere and deceleration of the polar night jet. The latter then exerts a downward influence into the troposphere maximizing in the North Atlantic region, which establishes itself within 2 weeks. We compare the forecasted NAO index in our simulations with those from several operational forecasts of the winter 2009/2010 made at the ECWMF, and highlight the importance of relatively high horizontal resolution.

Keywords Seasonal forecasting $\cdot$ North Atlantic Oscillation · Cryosphere

\section{Introduction}

The winter 2009/2010 was remarkably cold and snowy over North America and across Eurasia, from Europe to the Far East, bringing record snow storms and bitter cold air outbreaks (Wang and Chen 2010; Cohen et al. 2010; Hori et al. 2011). These cold conditions over North America and Europe coincided with one of the most extreme negative phases of the North Atlantic Oscillation (NAO) in the observational record (e.g. Fereday et al. 2012). The North Atlantic jet stream also had an extremely pronounced southward displacement through most of the DecemberFebruary period (Santos et al. 2013).

Several studies investigated the external factors that, in addition to internal atmospheric variability, could have potentially contributed to the negative NAO phase: sea surface temperature (SST) over the Atlantic or over the equatorial Pacific, late-summer Arctic sea ice extent, landatmosphere coupling involving the Eurasian snow cover, stratospheric polar vortex variability and low solar shortwave radiative forcing (Cohen et al. 2010; Fereday et al. 
2012; Jung et al. 2011). Jung et al. (2011) noted that, in the operational forecasts with the European Centre for Medium-Range Weather Forecasts (ECMWF) coupled ocean-atmosphere ensemble prediction system started at the beginning of December or January, the NAO index rapidly relaxed to near-neutral values following the initial negative anomaly. Through a series of dedicated experiments with the ECMWF monthly coupled forecasting system, they eliminated successively each of the above-mentioned factors as capable of producing the magnitude of the observed NAO anomaly. Their conclusion was that natural atmospheric variability was responsible for the onset and persistence of the negative NAO phase. Intriguingly, in that paper, other coupled forecasts with the ECMWF Variable Resolution Ensemble Prediction System (VAREPS) showed remarkable persistence of the initial NAO index in the late winter period.

The snow-covered land plays a key role in the climate system, and observational as well as studies using atmosphere-only or coupled ocean-atmosphere models have shown that the Eurasian snowpack in autumn influences the horizontal and upward propagation of planetary waves (PWs) and modulate the Arctic Oscillation (Allen and Zender 2011; Cohen et al. 2010; Orsolini and Kvamstø 2009; Smith et al. 2011; Henderson et al. 2012; Fletcher et al. 2009; Peings et al. 2012). Since the land-sea thermal contrast is a strong driver of PWs, it is not surprising that the presence of a continent-wide surface cooling due to an anomalously thick snowpack may modulate their amplitudes. Furthermore, recent studies demonstrate that initialization of the snowpack has an impact on subseasonal forecasts (Jeong et al. 2013; Orsolini et al. 2013).

In December 2009, the Eurasian snow cover extent was the second largest on record (Cohen et al. 2010). The observed snow depths anomalies at the beginning of autumn 2009 were not exceedingly large however. Figure 1 shows that the snow depth averaged over Eurasia $\left(40^{\circ} \mathrm{E}-140^{\circ} \mathrm{E} ; 40^{\circ} \mathrm{N}-75^{\circ} \mathrm{N}\right)$ derived from ERA-Interim reanalyses (hereafter, ERAINT, Dee et al. 2011) was below its climatological value in October 2009. However, it increased very rapidly throughout November and December, and it exceeded the long-term climatological value by the end of that period. Interestingly, an autumn snow cover advance index has been recently used in empirical statistical prediction model of the NAO predictor (Cohen and Jones 2011; Brands et al. 2012).

In this study, we have revisited the possible influence of the Eurasian snowpack on the negative NAO in early winter 2009/2010 in coupled forecasts. Our strategy has been to follow the approach developed in the GLACE2 (Global Land Atmosphere Coupling Experiments, e.g. Koster et al. 2011) model inter-comparison study. To this end, we carry out twin ensemble forecasts using either realistic or

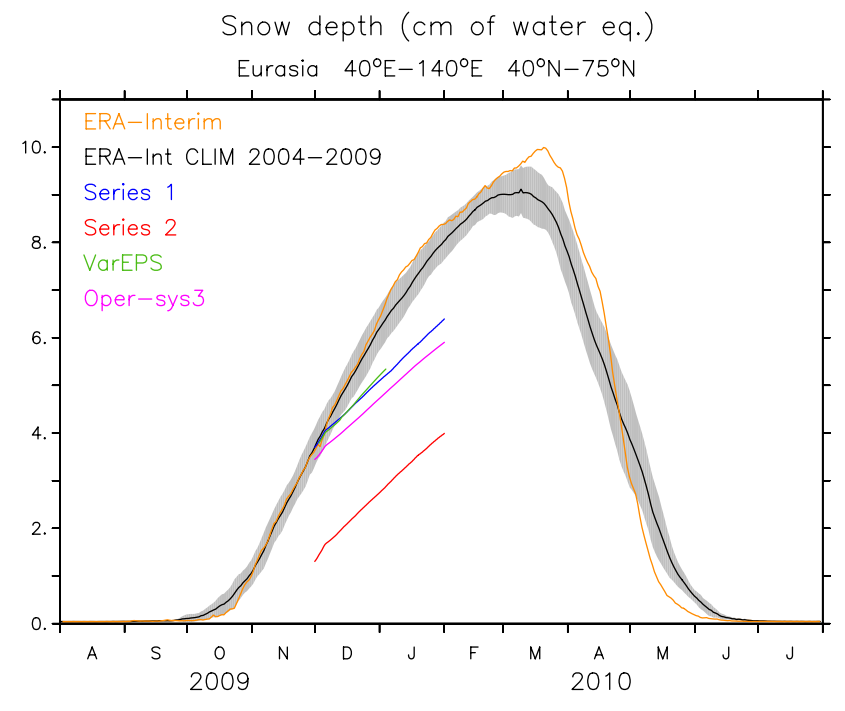

Fig. 1 Snow depth averaged over Eurasia $\left(40^{\circ} \mathrm{E}-140^{\circ} \mathrm{E} ; 40^{\circ} \mathrm{N}-75^{\circ} \mathrm{N}\right)$ from August 2009 to July 2010 in ERAINT (orange curve) along with the climatology over 2004-2009 (black curve) and a one-standard-deviation spread (grey shading). Also shown are snow depths averaged over Eurasia for the Series 1 (blue curve) and Series 2 (blue curve) forecasts started December 1st, for the VAREPS forecast started December 3rd (green curve) and operational S3 forecasts started December 1st (pink curve). Units are $\mathrm{cm}$ of water equivalent. Ensemble-mean forecasts are used

randomized snow initial condition, so that forecast differences can be attributed to the snow initialization.

\section{Model simulations}

The forecasts were made with the coupled ocean-atmosphere forecast model of the ECMWF. While GLACE2 was devoted to the impact of soil moisture on subseasonal forecasts in the warm season, we have transposed their methodology to investigate the impact of snow in the cold season. Further details about these runs -which we will refer to as the SNOWGLACE runs-are provided in Orsolini et al. (2013).

We performed two 11-member ensemble retrospective 2-month forecasts starting on December 1, 2009. These are part of a larger set of winter forecasts covering the period 2004-2009, described in further detail in Orsolini et al. (2013). This larger set will be used for normalization and calibration. The experiments are true forecasts, with no use of future information. Both series have realistic initial atmospheric and oceanic states, derived from ERAINT and from oceanic analyses, respectively. The initial land states for both ensembles are derived from ERAINT, but differ wherever snow is present on land (in either hemisphere). In the first ensemble, hereafter Series 1, the snow-related prognostic variables (snow density, albedo, temperature, 


\section{Snow Depth (cm) Lead 0 (1-15 day) 01-DEC-2009 IC 95\%}

(a) Series 1 minus Series 2

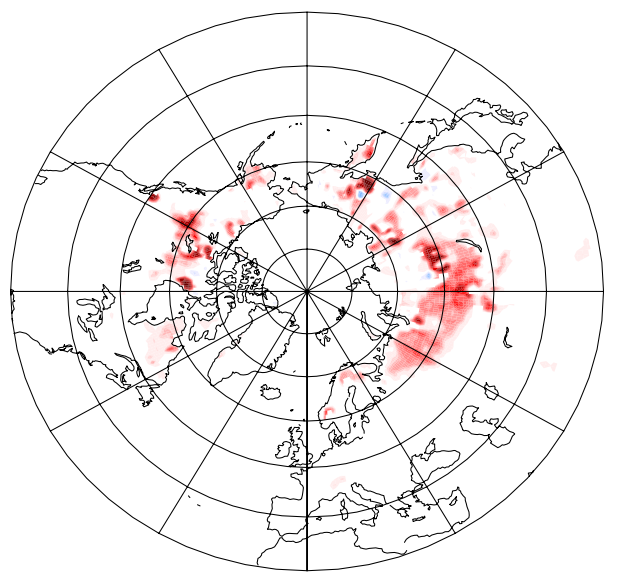

(b) Series 1 minus Climatology

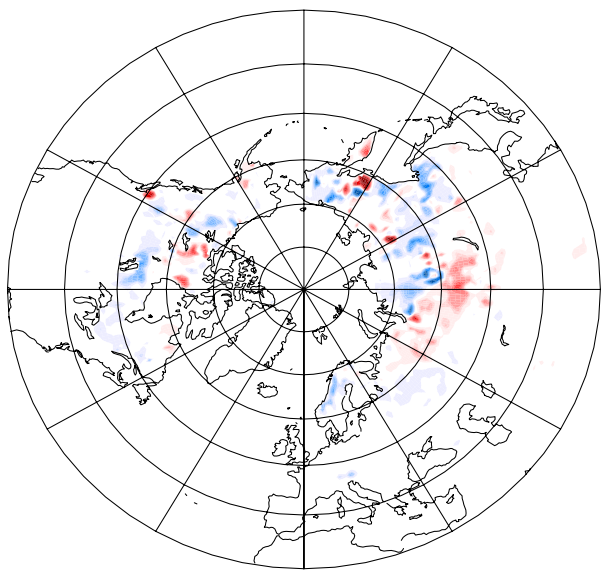

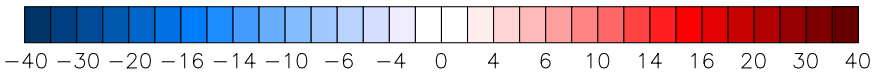

Fig. 2 Map of snow depth difference between Series 1 and Series 2 at the 0-day lead (a), showing the high snow conditions in Series 1, as well as the difference between Series 1 and the ERAINT climatology for the corresponding period (b)

and snow water equivalent) are realistically initialized from ERAINT and are identical for all members. In the second set however, hereafter Series 2, the snow-related variables are randomized separately for each member, taken from earlier autumn start dates and other years. Since snow initial conditions in Series 2 are taken from earlier start dates, Series 2 has smaller snow depths than Series 1 . The difference between the Series 1 and Series 2 ensemble means can hence be interpreted as a composite difference (high - low snow). The scrambling of initial dates across the autumn when the snow seasonal cycle induces rapid variations in snow depth implies that the snow perturbations in Series 2 can be large. Figure 1 also shows the evolution of the ensemble-mean Eurasian snow depth for both Series 1 and Series 2, and it can be seen that at the forecast start, Series 2 has a lower depth roughly corresponding to a 1-month lag in the seasonal cycle (e.g. November instead of December).

We used the cycle 36R1 atmospheric model, which has 62 levels with an upper boundary near $5 \mathrm{hPa}$ and a relatively high spatial resolution (T255). This model cycle is close to the one used to produce ERAINT re-analyses, which will be used to validate the forecasts. It also has a new one-layer snow scheme that has been shown to reduce a warm forecast bias in surface temperature during winter over snow covered areas, due to increased snow depth and a better insulating snowpack (Dutra et al. 2010, 2012). Several diagnostics were averaged in 15-day sub-periods, four per forecast, corresponding to lead time of 0 (days 1-15), 15 (days 16-30), 30 (days 31-45) and 45 (days 46-60) days, respectively. The outputs are re-gridded to a 1 degree by 1 degree grid.

\section{Forecasts of the NAO}

Figure 2 shows a map of the Series 1 - Series 2 difference in snow depth at the zero lead, hence revealing the high snow conditions in Series 1, as well as the difference between Series 1 and climatology. While the mean Eurasian snow depth was close to climatology (Fig. 1), there is actually less snow than climatology in the east and north of Siberia. Figure 3 shows the difference between the two simulations (Series 1 - Series 2) in 15 day-averaged surface temperature for the 0- and 15-day lead times, with statistically significant values at the $95 \%$ level highlighted (green contour). Starting at the 0-day lead, cold anomalies in surface temperature are seen over snow-covered land at mid and high latitudes over Eurasia and North America, mostly statistically significant over Eurasia. Hence the presence of a thicker snowpack in Series 1 readily leads to an anomalous surface cooling (Dutra et al. 2010; Peings et al. 2012; Orsolini et al. 2013). At the 15-day lead time, the differences in Series 1 - Series 2 in surface temperature (Fig. 3), sea level pressure (SLP) and 200-hPa wind speed and SST (Fig. 4) display the characteristics of negative NAO anomalies across the Atlantic: i.e. a quadrupole in surface temperature, a north/south dipole in SLP, a jet stream displaced southwards and a tripole of SSTs. The surface temperature differences are not limited to the quadrupolar pattern (cold over Central Europe and warm over Northeast America-Greenland, with opposite anomalies to further south), and cold anomalies are present over China and the Far East. 


\section{$2 m$ Air Temperature Series1 minus Series2 95\%}

(a) Lead 0 (1-15day)

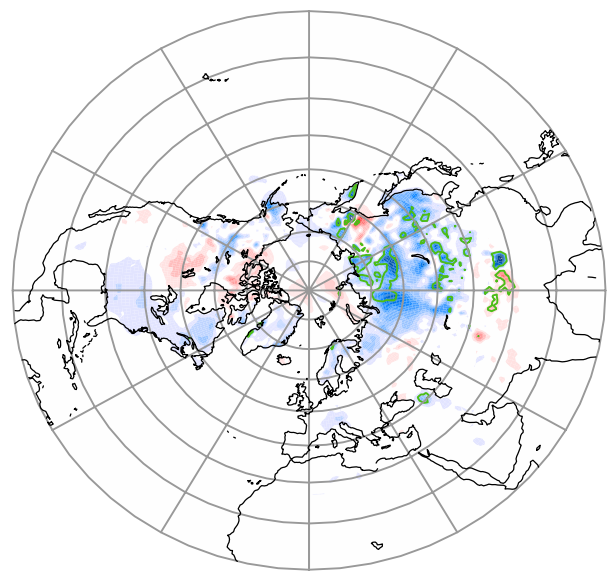

(b) Lead 15 (16-30day)

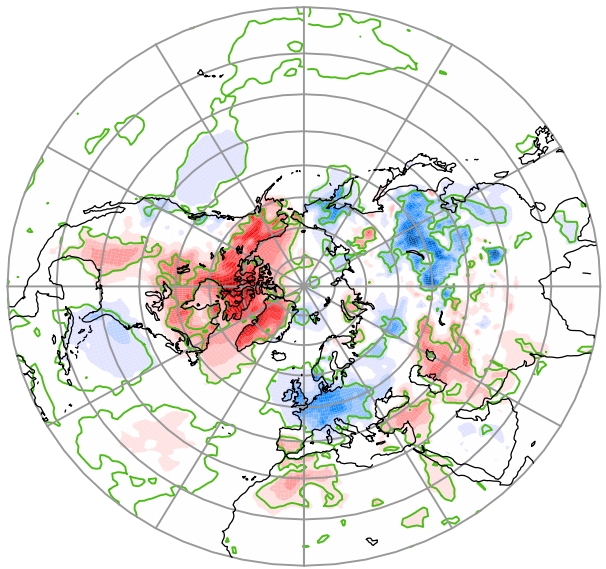

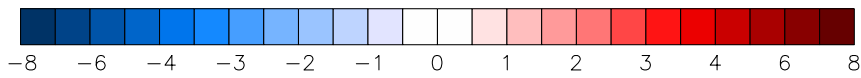

Fig. 3 Difference between Series 1 and Series 2 surface temperature at the a 0 - and $\mathbf{b}$ 15-day lead times, as 15-day averages. Only values significant at the $95 \%$ confidence level are shown. Units are ${ }^{\circ} \mathrm{C}$

Series 1 minus Series 2 Lead 15 (16-30 day) 95\%

(a) Mean Sea Level Pressure (hPa)

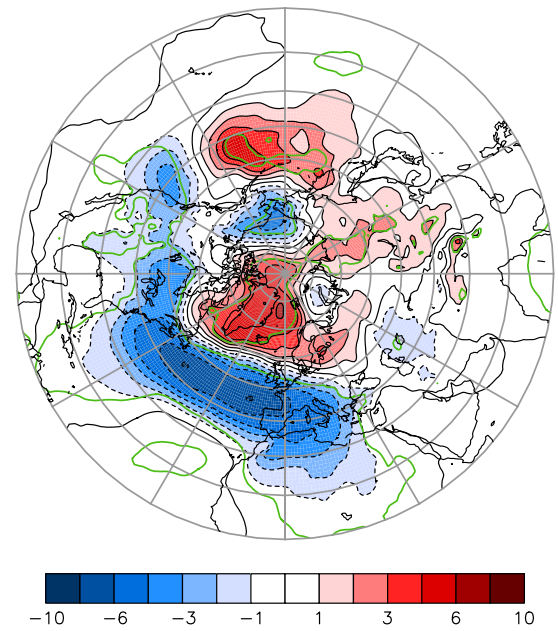

(b) $200 \mathrm{hPa}$ Wind Speed $\left(\mathrm{m} \mathrm{s}^{-1}\right)$
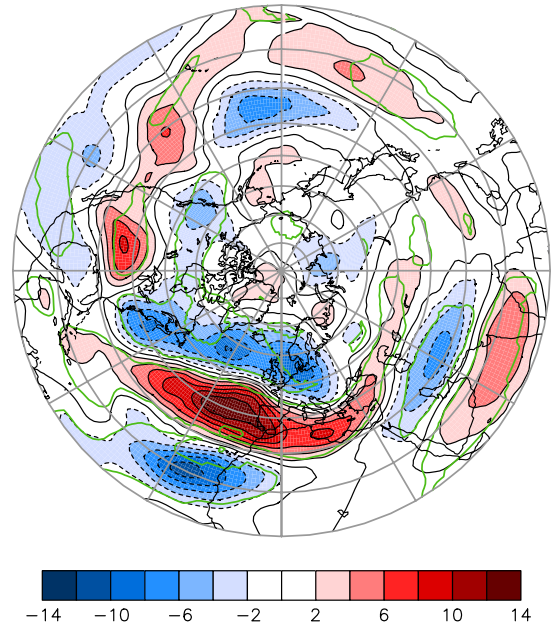

(c) Sea Surface Temperature $\left({ }^{\circ} \mathrm{C}\right)$
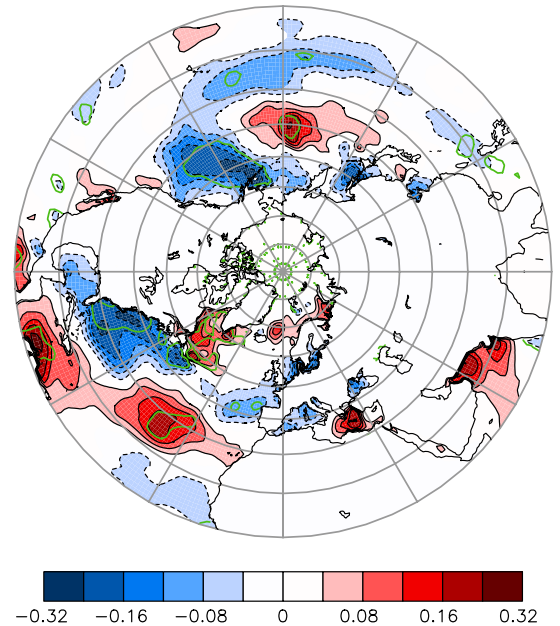

Fig. 4 Same as Fig. 2 for a sea level pressure (SLP), b 200-hPa wind speed and c SSTs but at the 15-day lead time. Only values significant at the $95 \%$ confidence level are shown. Units are $\mathrm{hPa}, \mathrm{m} / \mathrm{s}$ and ${ }^{\circ} \mathrm{C}$, respectively

These differences are also reflected in the normalized NAO index (Fig. 5). Following Li and Wang (2003), we use an index based on normalized SLP anomaly differences between $65^{\circ} \mathrm{N}$ and $35^{\circ} \mathrm{N}$ averaged over the $80^{\circ} \mathrm{W}-30^{\circ} \mathrm{E}$ longitudinal band. The daily SLP anomaly is calculated as a deviation from the climatology of our ensemble of forecasts (66 forecasts, corresponding to six 11-member started December 1 over the years 2004-2009). The daily SLP anomaly is then normalized by its standard deviation over the 2-month period (1 December 2009-31 Jan 2010). For ERAINT, the SLP anomaly is based on the 2004-2009 daily climatology and the normalization is carried out in a similar fashion as the model forecasts. At the 0-day lead, the 15-day averaged ensemble-mean indices for Series 1 and Series 2 are nearly identical, having the same initial atmospheric conditions. However, Series 2 relaxes quickly to near-neutral NAO conditions, while the initial negative NAO index is maintained throughout the 2 months in Series 


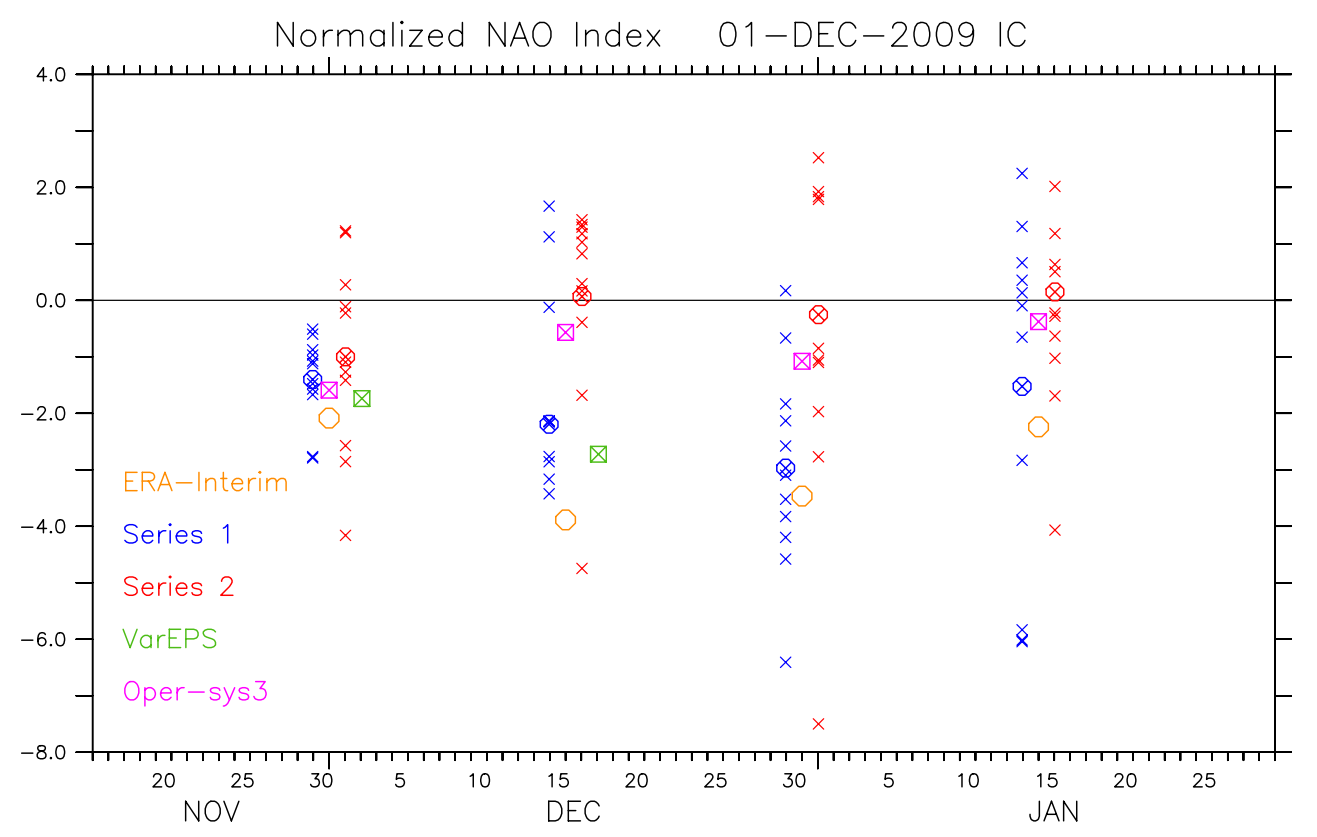

Fig. 5 Normalized NAO index based on SLP anomaly differences between $65^{\circ} \mathrm{N}$ and $35^{\circ} \mathrm{N}$ averaged over the $80^{\circ} \mathrm{W}-30^{\circ} \mathrm{E}$ longitudinal band. Indices are shown for Series 1 (blue crosses and circled cross for ensemble-mean), Series 2 (same in red), ERAINT (orange circles), and for the ensemble-mean VAREPS forecasts (green squares)

1. Hence, in presence of a thick snowpack, the forecasted NAO index in Series 1 remains negative and is closer to the observations than Series 2. While the accentuation of the negative NAO index in December and the swing to a more weakly negative index in January are not captured in either forecast, it appears that the snowpack contributes to the persistence of the initially negative NAO. Other forcings or internal variability may govern the evolution of the observed NAO, but our argument is that the thick snowpack contributes to the negative phase maintenance.

This is further supported by additional analysis of the operational monthly forecasts carried out in December 2009 with the ECMWF Variable Resolution Ensemble Prediction System (VAREPS; Vitart et al. 2008). These runs are very similar to our SNOWGLACE runs in that they use the same model cycle and land surface module, but they are launched weekly and are of shorter duration (32 days) with a large ensemble size (51 members). The only differences are that (1) the snow is initialized using operational analyses rather than ERAINT in the VAREPS forecasts, (2) the latter have a higher horizontal resolution (T399) during the first 10 days while having the same T255 resolution than our SNOWGLACE runs thereafter, and (3) the ocean coupling is introduced at day 10 . The normalization of the NAO index for the VAREPS ensemble-mean forecasts is based on the daily SLP using VAREPS reforecasts started in early December over the same 2004-2009 period. For and for the ensemble-mean operational (S3) forecasts (pink squares). Indices are for 15-day periods and plotted at the beginning of each period (e.g. December 1 corresponds to December 1-15). Symbols for the different forecast set are shifted by a day along the time axis for clarity of the display

the VAREPS forecasts from December 3 (the closest day available to December 1 start date of our SNOWGLACE simulations), the 15-day averaged ensemble-mean NAO index remains close to its initial value, just as the Series 1 simulations (Fig. 4, green squares).

To further support the notion that a relatively high horizontal resolution and realistic snow initialization is important for the maintenance of the NAO initial negative conditions, we also analysed the then-operational seasonal forecasts (System 3; Stockdale et al. 2011) which were referred to in Jung et al. (2011; their Fig. 1). These forecasts are initialised with realistic, operational initial snow conditions and consist of 41 members; they were also normalized relative to the same 2004-2009 period. It can be seen on Fig. 5 that the initially negative values of the NAO index (Fig. 5, pink squares) do not persist in these lower resolution (T159) simulations.

We next demonstrate that the complete feedback involves the stratosphere. We will come back to the role of the horizontal resolution in the Discussion section.

\section{Role of the stratosphere in the snow/NAO coupling}

Fluctuations in the strength of the wintertime polar stratospheric vortex contributes to the NAO variability, both 


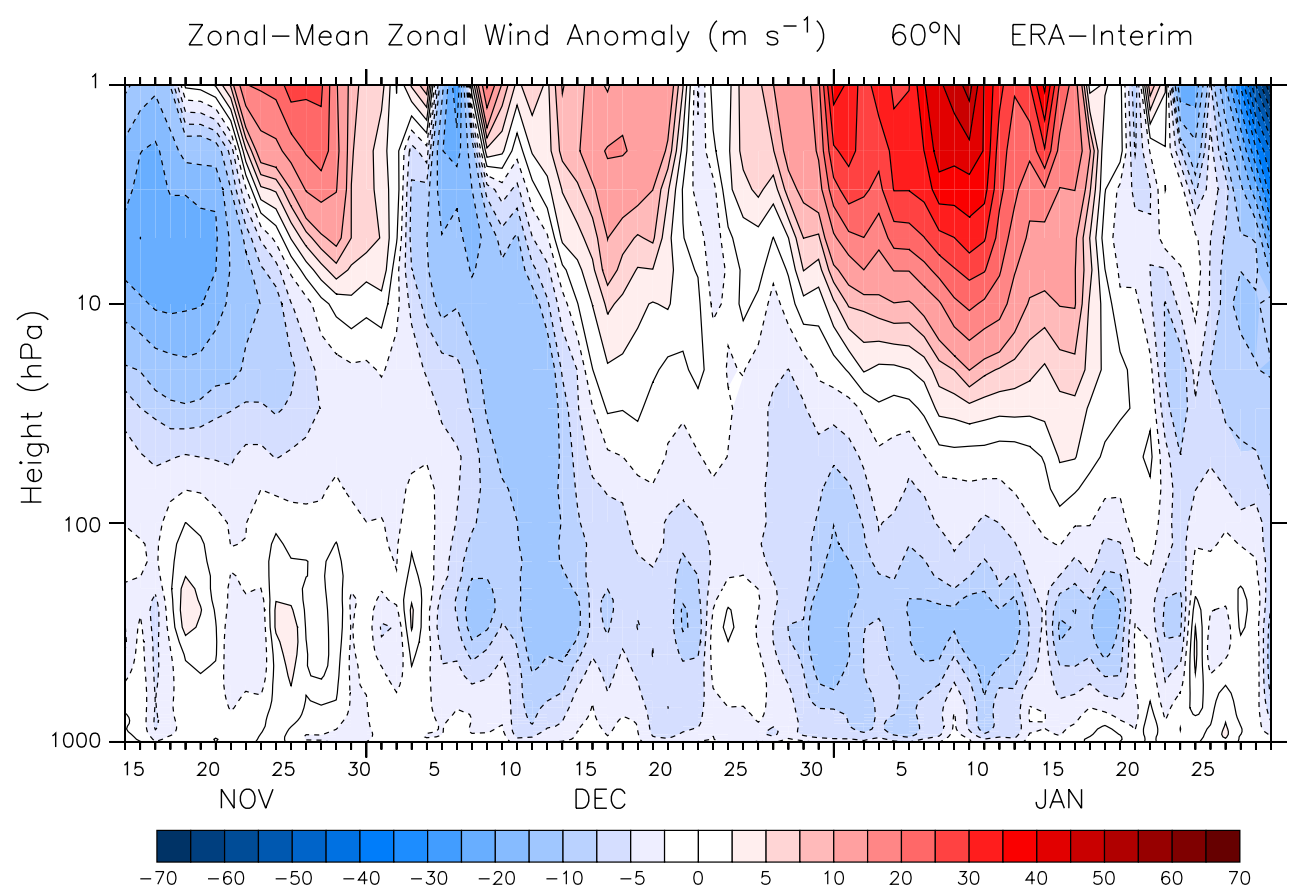

Fig. 6 Height/time cross-section of zonal-mean zonal wind anomaly at $60^{\circ} \mathrm{N}$ from ERAINT in winter 2009/2010. Anomaly is calculated from the period 2004-2009. Units are $\mathrm{m} / \mathrm{s}$

in observations and models (e.g. Baldwin and Dunkerton 2001; Orsolini et al. 2011; Shaw et al. 2014). During the 2009/2010 winter, the stratospheric zonal-mean zonal flow at $60^{\circ} \mathrm{N}$ (Fig. 6) was anomalously weak in the second half of November and in early December, before a brief period of intensification in early January and a major stratospheric warming in late January (Wang and Chen 2010; Cohen et al. 2010; Ayarzagüena et al. 2011; Dörnbrack et al. 2012). The occurrence of the early December stratospheric vortex weakening is followed by a period (approx. from December 5-25) of weaker zonal-mean flow in the mid and lower troposphere (e.g. $500 \mathrm{hPa}$ and below, Fig. 6). That period is characterized by a southwardly displaced jet over the Atlantic and marks the onset of the large negative NAO (Wang and Chen 2010; Santos et al. 2013). The downward propagation of the stratospheric jet intensification from $1 \mathrm{hPa}$ in early January to tropopause level by mid-January is quite clear (Fig. 6), and there is eastward zonal wind acceleration in the troposphere later during the month (approx. January 20-29). This is also a period when the Atlantic jet stream briefly returns to more northern latitudes (Santos et al. 2013). Hence, the evolution of the NAO through the winter is qualitatively consistent with a stratospheric influence. However, hindcasts with nudged stratospheric variables offer contradictory results concerning the causal role of the stratosphere on the NAO variability in winter 2009/10. On the one hand, the winter-mean $500 \mathrm{hPa}$ NAO pattern was better reproduced when the stratosphere was nudged as in Ouzeau et al. (2011) using the MeteoFrance Arpege model. Also, the high-top model in Fereday et al. (2012) which better resolves the stratosphere and better predicts stratospheric sudden warmings showed improved NAO forecasts. On the other hand, Jung et al. (2011) found that nudging the ECMWF forecast model in the stratosphere did not improve NAO forecasts.

Even if internal variability or stratospheric influence are governing the NAO fluctuations, our twin simulations show that the stratospheric circulation is readily affected by the presence of the cold surface anomalies induced by the anomalously thick snowpack. Figure 7 shows the quasi-stationary zonal-mean meridional eddy heat fluxes for Series 1, Series 2 and their difference, averaged over December 16-30. The increased fluxes at the 15-day lead time in Series 1 implies enhanced vertical propagation of quasi-stationary PWs. We further note that, in the polar stratosphere, weakly negative heat fluxes are found in Series 2 , implying downward wave propagation.

Figure 8 shows the 15-day averaged zonal-mean zonal wind for ERAINT as well as for Series 1, Series 2 and their difference. Consistent with the eddy heat flux enhancement, the vortex is weaker in Series 1 than in Series 2. Figure 8 also shows the corresponding zonal winds for the VAREPS and for the operational (S3) forecasts, along with the difference from their initial wind condition. Figure 8 reveals that a weakening of the stratospheric jet has occurred in VAREPS but only very weakly so in S3, consistent with the 


\section{Meridional Eddy Heat Flux $\left(\mathrm{K} \mathrm{m} \mathrm{s}^{-1}\right)$ 16-30 Dec 2009}

(a) Series 1

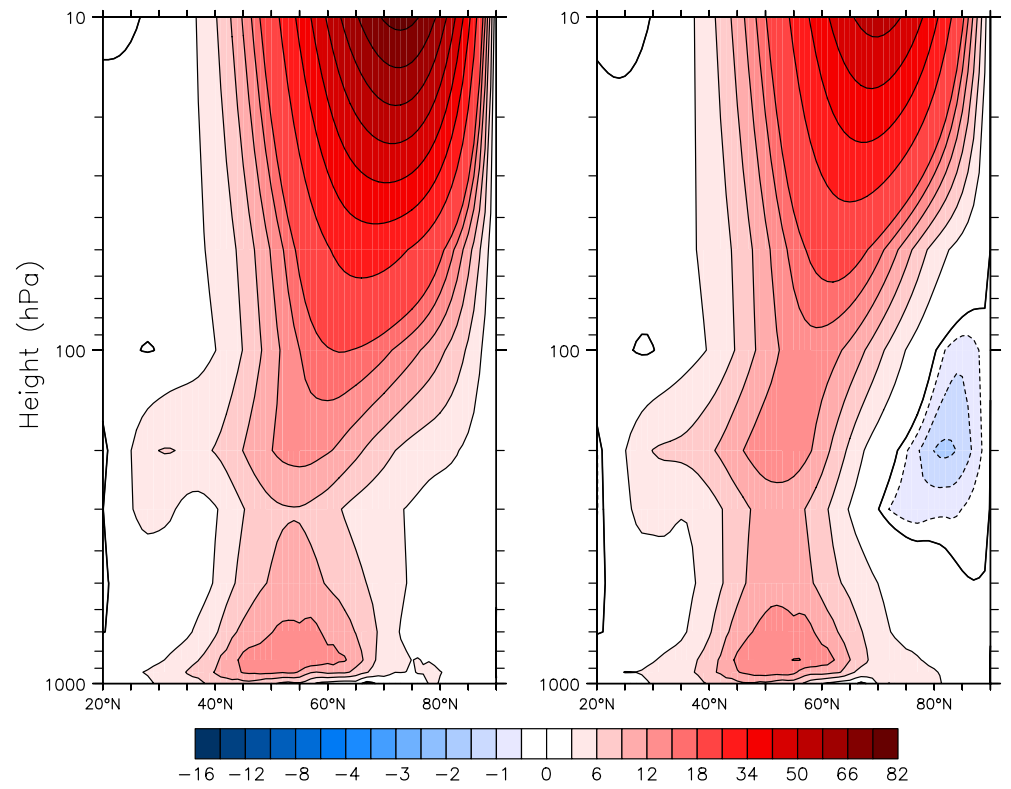

(c) Series 1 minus Series 2

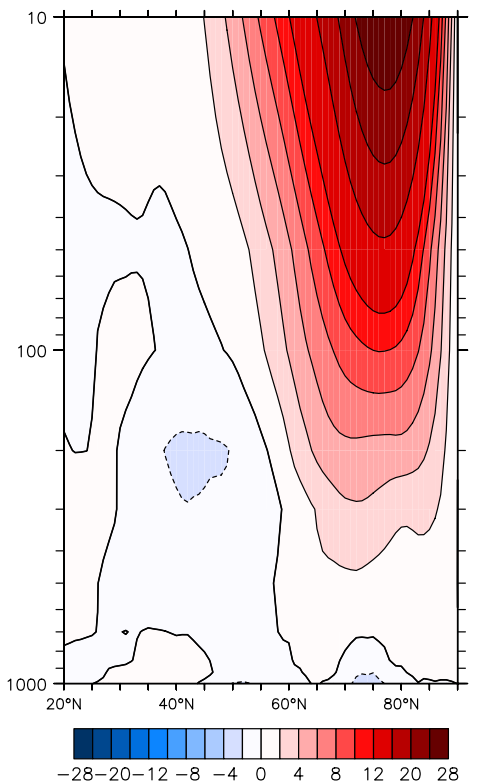

Fig. 7 Height/latitude cross-section of 15-day averaged zonal-mean meridional eddy heat flux in a Series 1, b Series 2 and $\mathbf{c}$ their difference (Series 1 - Series 2) at the 15-day lead time. Units are $\mathrm{m} \mathrm{K} / \mathrm{s}$

snow-NAO coupling via the stratosphere acting similarly in the high-resolution forecasts VAREPS as in Series 1.

From the comparative analysis of our twin forecasts, we can deduce that the weaker vortex in Series 1 readily exerts an influence at the surface, modulating the NAO: the response maximizing over the North Atlantic appears once the stratospheric jet is being decelerated at the 15-day lead time (see Fig. 4). This is consistent with model studies of stratospheric downward influence on the surface circulation having both a fast (order of a week) component in addition to the slowly-propagating downward influence emphasized in Baldwin and Dunkerton (2001) or Cohen et al. (2014). For example, composites of weak vortex events in the Meteo-France ARPEGE model in Orsolini et al. (2011) showed a tropospheric response limited to the North Atlantic during their onset and growth stages, as the stratospheric vortex starts to weaken (1 month to 2 weeks prior to the warming peak). Similarly rapid tropospheric and surface responses to stratospheric fluctuations were found in composites of stratospheric heat flux events in Shaw et al. (2014). Fletcher et al. (2009) studied the response to snow forcing in simulations with an atmospheric general circulation model, and also found an initial response in the first 2 weeks, which depended on the initial stratospheric state.

\section{Discussion and summary}

The presence of an anomalously high snow depth over Eurasia induces an anomalous surface and lower atmospheric cooling (Dutra et al. 2010; Orsolini et al. 2013). The cold hemispheric-wide temperature anomaly induces enhanced vertical wave planetary propagation into the stratosphere, contributing to decelerate the polar stratospheric jet. The rapid tropospheric response to the decelerating stratospheric jet maximizes over the North Atlantic sector, and readily appears on a 15 -day time scale.

To demonstrate some robustness of our results with regard to the start date, we briefly discuss forecasts initiated on the November 15. For start dates in November, the perturbed snow in Series 2 can be higher or lower than in Series 1 , hence a conditional compositing is used, whereby one retains only the ensemble members in Series 2 for which the initial snow is lower than Series 1, in order to make a "high-low" snow composite. In the supplemental Fig. S1, the index for Series 1 is seen again to be closer to re-analyses than the index for Series 2, which becomes rapidly neutral. Hence, the results are similar to the December 1 start date. In the supplemental Fig. S2, composite differences between $\mathrm{S} 1$ and S2 at the 30-day lead show similar 


\section{Zonal-Mean Zonal Wind $\left(\mathrm{m} \mathrm{s}^{-1}\right)$ 16-30 Dec 2009}

(a) ERA-Interim
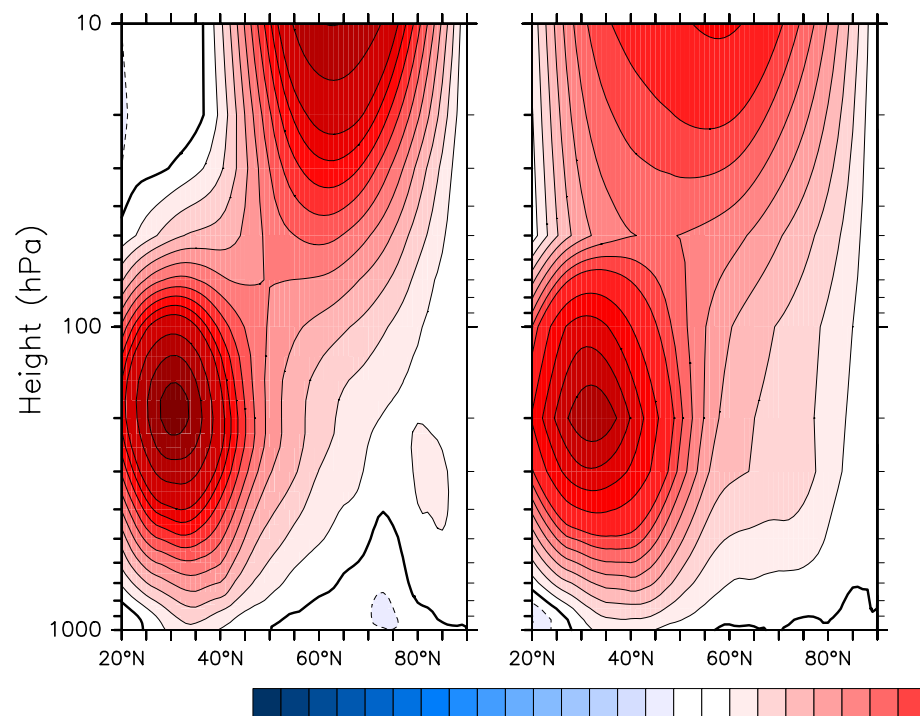

$-60-50-40-30-20-15-10-5005$

(e) VarEPS

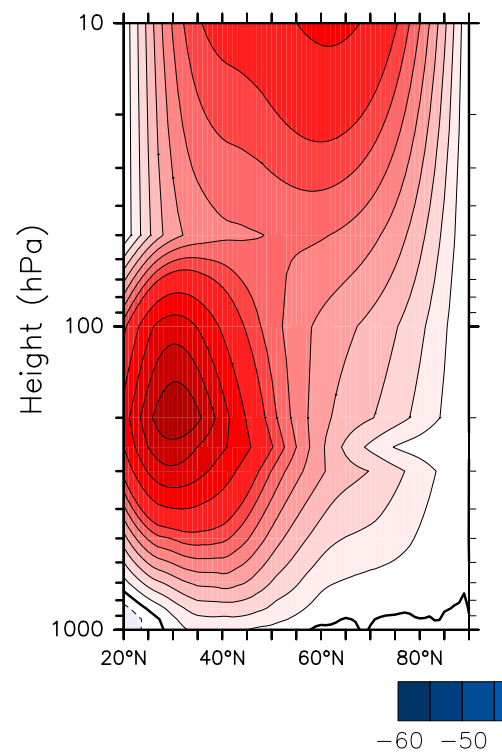

(b) Series 1

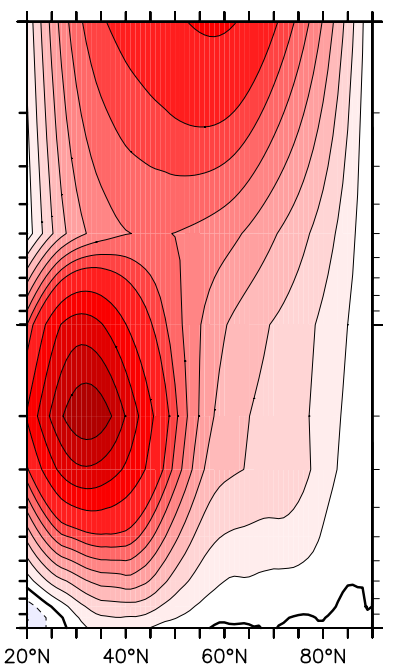

(c) Series 2

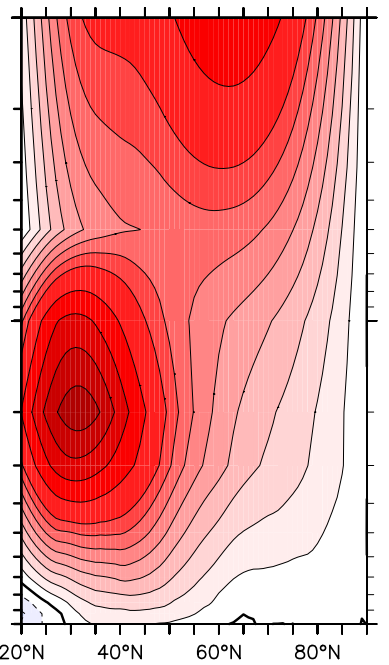

$20^{\circ} \mathrm{N} \quad 40^{\circ} \mathrm{N} \quad 60^{\circ} \mathrm{N} \quad 80^{\circ} \mathrm{N}$

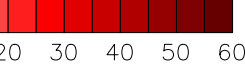

(g) VarEPS minus IC

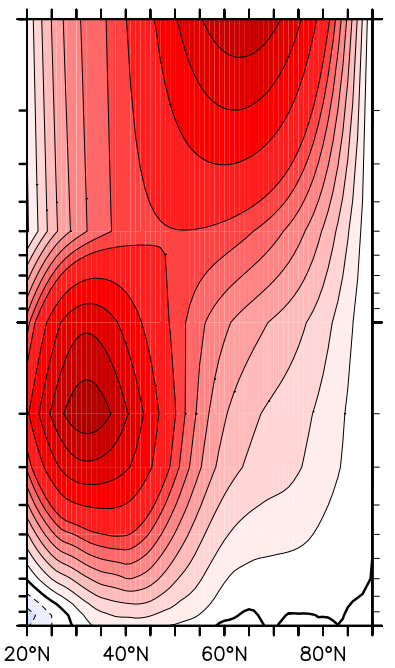

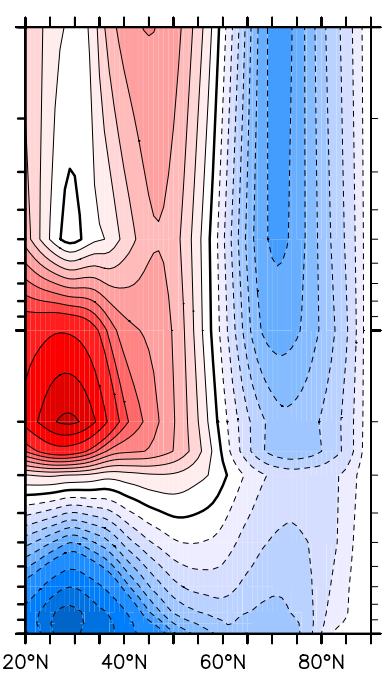

(d) Series 1 minus Series 2

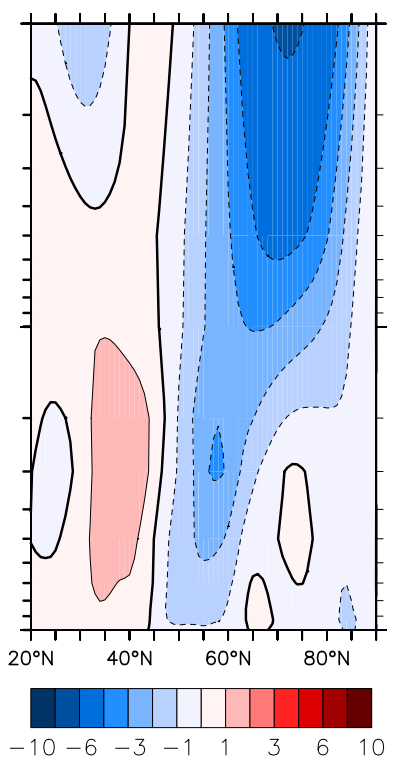

(h) Oper-sys 3 minus IC

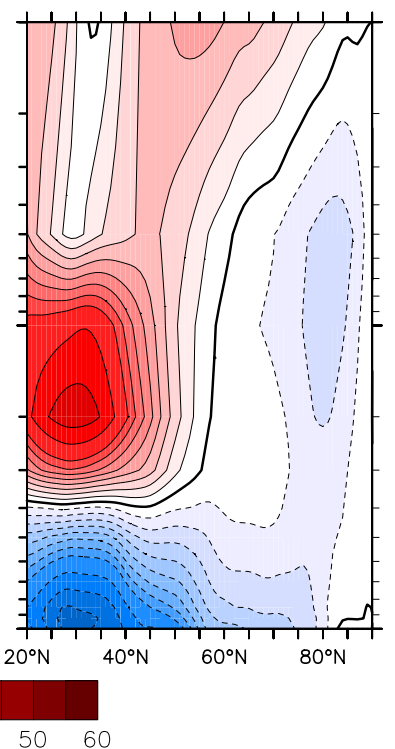

Fig. 8 Height/latitude cross-section of 15-day averaged zonal-mean zonal winds in a ERAINT, b Series 1, $\mathbf{c}$ Series 2, and $\mathbf{d}$ their difference (Series 1 -Series 2), as well as for e VAREPS and $\mathbf{f}$ operational forecast S3, and the difference from their initial conditions in the latter two cases $(\mathbf{g}, \mathbf{h})$. All forecast cross-sections are at the 15-day lead time. Units are $\mathrm{m} / \mathrm{s}$ results as for Fig. 4, with a displaced jet stream and SLP anomalies characteristic of a negative NAO.

Differences in snow depths used for initialization between operational analyses (as used in VAREPS or S3) or ERAINT (as used in SNOWGLACE2) are not very large (see Fig. 1). It hence appears that sufficiently high horizontal resolution like the one used in our SNOWGLACE2 or the VAREPS forecasts ( $>$ T255) is necessary to capture the
snow/NAO coupling that maintains the negative NAO. The simulations in Jung et al. (2011), based on the same atmospheric model version as our SNOWGLACE2 runs (cycle 36r1), were at a lower horizontal resolution (T159). Climate model simulations investigating the snow/stratosphere coupling tend to be at a lower resolution too (e.g. Orsolini and Kvamstø 2009; Hardiman et al. 2008; Furtado et al. 2015). We surmise that the relatively high horizontal resolution is 
500 hPa Eddy Geopotential Height (m) Climatology 1-30 day

(a) Series 1

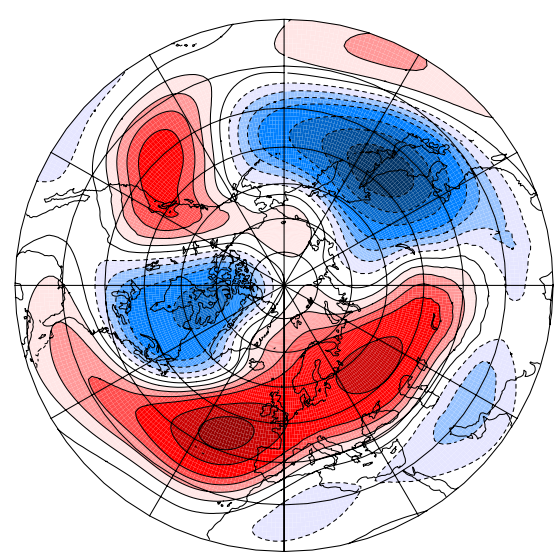

(b) VarEPS

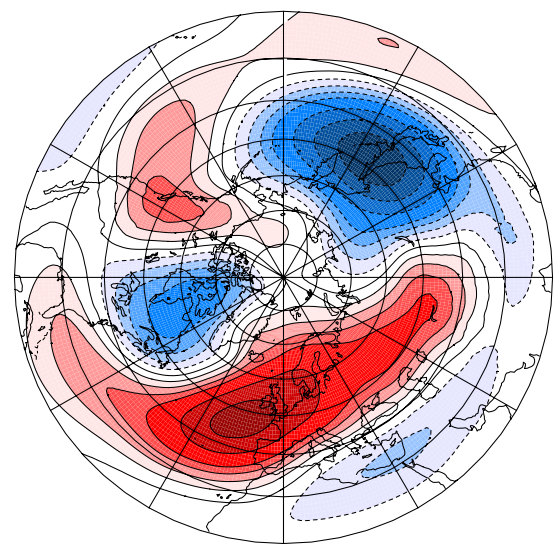

(c) Oper-sys3

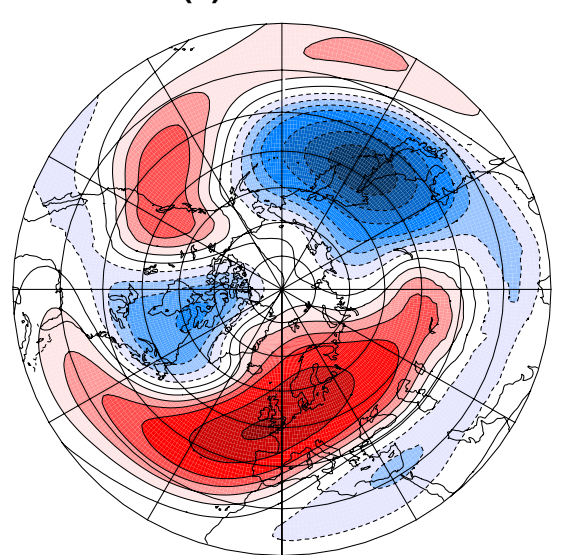

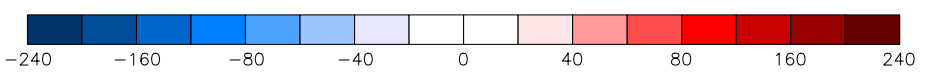

Fig. 9 Map of climatological geopotential eddy at $500 \mathrm{hPa}$, in December, for a Series 1, b VAREPS, c Operational S3. Climatology is calculated over the 2004-2008 period (a) or the 1991-2008 period (b, c)

an important factor because resolution-dependent model biases can appear very fast. Figure 9 shows the climatological eddy geopotential height at $500 \mathrm{hPa}$ in S1, VAREPS and S3, during the first month of forecast (December). For Series 1, the mean eddy is evaluated over 2004-2008 (2009 is being excluded), while for the other forecast models, the 1998-2010 period is used. One can see that, in the low resolution S3 model, the ridge extending across Siberia is not so elongated zonally. This could contribute to a weaker interaction of the snow-induced anomaly with the background climatological wave (e.g. through linear interference involving the background meridional wind and temperature, see Smith et al. 2011). However, better resolution of topography and difference in the land surface scheme between the models could also contribute. We also note that the operational model $\mathrm{S} 3$ has a stronger positive bias in the lower stratospheric zonal jet strength than the other models.

This rapid snow/NAO coupling displayed in our simulations ought to be also captured in an atmosphere-only model, as up to the monthly timescale, the SSTs are responding to the atmospheric forcing (Fig. 2). Nevertheless, coupled ocean-atmosphere simulations are needed to resolve the surface/stratosphere coupling on the longer monthly to seasonal time scale (e.g. Henderson et al. 2012). In the real world, the initial swing into a NAO negative phase may be forced by internal dynamical variability or by stratospheric forcing. An established negative NAO phase would be associated with an increase in Eurasian snow depth (e.g. Seager et al. 2010, their Fig. 2). In turn, our simulations suggest that the thicker snow depths over Eurasia contribute to maintain the NAO negative phase, leading to further increase in snow depths over Eurasia. The snow depth increase over Eurasia in our forecasts is actually weaker than observed (Fig. 1), hence the snow/NAO feedback could well be underestimated by our diagnostics. Recent work suggests that the inclusion of a 1-layer snow scheme (like used in the SNOWGLACE simulations) in the ECMWF EC-Earth model has reduced but not eliminated a warm surface bias over Eurasia in winter. Multi-layer snow schemes would alleviate the warm bias further (Dutra et al. 2012). This warm bias could be related to the negative bias in snowy precipitation. Additional work would be needed to address and correct the deficit in snow depth build-up in all the forecast models used here (see Fig. 1).

The robustness of the results presented here as a case study of the winter 2009/2010 needs to be further assessed over a longer period. In the future, we plan to perform a decadal set of SNOWGLACE simulations covering more recent cold winters as well as to extend the comparison to other models.

Acknowledgments YOR and RS were supported by the Norwegian Research Council through the projects EPOCASA (Grant 229774/E10), and ERA_RUS ACPCA (Grant 223046), and YOR by the EU-FP7 SPECS (Seasonal-to-decadal climate Prediction for the improvement of European Climate Services, Grant 308378).

\section{Compliance with ethical standards}

Conflict of interest The authors declare that they have no conflict of interest. 
Open Access This article is distributed under the terms of the Creative Commons Attribution 4.0 International License (http://creativecommons.org/licenses/by/4.0/), which permits unrestricted use, distribution, and reproduction in any medium, provided you give appropriate credit to the original author(s) and the source, provide a link to the Creative Commons license, and indicate if changes were made.

\section{References}

Allen RJ, Zender CS (2011) Forcing of the Arctic Oscillation by Eurasian snow cover. J Clim 24:6528-6539. doi:10.1175/2011 CLI4157.1

Ayarzagüena B, Langematz U, Serrano E (2011) Tropospheric forcing of the stratosphere: a comparative study of the two different major stratospheric warmings in 2009 and 2010. J Geophys Res 116:D18114. doi:10.1029/2010JD015023

Baldwin MP, Dunkerton TJ (2001) Stratospheric harbingers of anomalous weather regimes. Science 294:581-584

Brands S, Manzanas R, Gutierrez JM, Cohen J (2012) Seasonal predictability of wintertime precipitation in Europe using the snow advance index. J Clim 25:4023-4028

Cohen J, Jones J (2011) A new index for more accurate winter predictions. Geophys Res Lett 38:L21701

Cohen J et al (2010) Winter 2009/10: a case study of an extreme Arctic Oscillation event. Geophys Res Lett 37:L17707. doi:10.1029/ 2010GL044256

Cohen J, Furtado J, Jones J, Barlow M, Whittleston D, Entekhabi D (2014) Linking Siberian snow cover to Precursors of stratospheric variability. J Clim 27:5422-5432

Dee DP et al (2011) The ERA-interim reanalysis: configuration and performance of the data assimilation system. Q J R Meteorol Soc 137:553-597. doi:10.1002/qj.828

Dörnbrack A, Pitts MC, Poole LR, Orsolini YJ, Nishii K, Nakamura H (2012) The 2009-2010 Arctic stratospheric winter-general evolution, mountain waves and predictability of an operational weather forecast model. Atmos Chem Phys 12:3659-3675. doi:10.5194/acp-12-3659-2012

Dutra E, Balsamo G, Viterbo P, Miranda PMA, Beljaars A, Schär C, Elder K (2010) An improved snow scheme for the ECMWF land surface model: description and offline validation. J Hydrometeorol 11:899-916. doi:10.1175/2010JHM1249.1

Dutra E, Viterbo P, Miranda PMA, Balsamo G (2012) Complexity ofsnow schemes in a climate model and its impacts on surface energy and hydrology. J Hydrometeorol 13:521-538

Fereday DR, Maidens A, Arribas A, Scaife AA, Knight JR (2012) Seasonal forecasts of northern hemisphere winter 2009/10. Env Res Lett. doi:10.1088/1748-9326/7/3/034031

Fletcher CG, Hardiman SC, Kushner PJ (2009) The dynamical response to snow cover perturbations in a large ensemble of atmospheric GCM integrations. J Clim 22(5):1208-1222. doi:10.1175/2008CLI2505

Furtado JC, Cohen JL, Butler AH, Riddle EE, Kumar A (2015) Eurasian snow cover variability, winter climate, and stratosphere-troposphere coupling in the CMIP5 models. Clim Dyn. doi:10.1007/s00382-015-2494-4

Hardiman SC, Kushner P, Cohen J (2008) Investigating the ability of general circulation models to capture the effects of Eurasian snow cover on winter climate. J Geophys Res 113:D21123. doi:10.1029/2008JD010623

Henderson G, Hanson B, Leathers D (2012) Circulation response to Eurasian versus North American anomalous snow scenarios in the Northern Hemisphere with an AGCM coupled to a slab ocean model. J Clim. doi:10.1175/JCLI-D-11-00465.1
Hori M, Inoue J, Kikuchi T, Honda M, Tachibana Y (2011) Recurrence of intraseasonal cold air outbreak during the 2009/2010 winter in Japan and its ties to the atmospheric condition over the Barents-Kara sea. SOLA 7:025-028. doi:10.2151/sola.2011-007

Jeong JH, Linderholm HW, Woo S-H, Folland C, Kim B-M, Kim S-J, Chen D (2013) Impact of snow initialization on subseasonal forecasts of surface air temperature for the cold season. J Clim 26:1956-1972. doi:10.1175/JCLI-D-12-001.59.1

Jung T, Vitart F, Ferranti L, Morcrette J-J (2011) Origin and predictability of the extreme NAO winter of 2009/10. Geophys Res Lett 38:L.07701. doi:10.1029/2011GL046786

Koster RD et al (2011) GLACE2: the second phase of the global land atmosphere coupling experiment: soil moisture contributrion to subseasonal forecast skill. J Hydrometeorol 12:805-822. doi:10. 1175/2011JHM1365.1

Li J, Wang JXL (2003) A new North Atlantic Oscillation index and its variability. Adv Atmos Sci 20(5):661-676

Orsolini YJ, Kvamstø N (2009) The role of the Eurasian snow cover upon the wintertime circulation: decadal simulations forced with satellite observations. J Geophys Res 114:D19108. doi:10.1029/ 2009JD012253

Orsolini YJ, Kindem IT, Kvamstø NG (2011) On the potential impact of the stratosphere upon seasonal dynamical hindcasts of the North Atlantic Oscillation: a pilot study. Clim Dyn 36:579. doi:10.1007/s00382-009-0705-6

Orsolini YJ, Senan R, Balsamo G, Doblas-Reyes FJ, Vitart F, Weisheimer A, Carrasco A, Benestad RE (2013) Impact of snow initialization on sub-seasonal forecasts. Clim Dyn. doi:10.1007/ s00382-013-1782-0

Ouzeau G, Cattiaux J, Douville H, Ribes A, Saint-Martin D (2011) European cold winter 2009-2010: How unusual in the instrumental record and how reproducible in the ARPEGE-Climat model? Geophys Res Lett 38:L.11706. doi:10.1029/2011GL047667

Peings Y, Saint-Martin D, Douville H (2012) A numerical sensitivity study of the influence of Siberian snow on the northern annular mode. J Clim 25:592-607. doi:10.1175/JCLI-D-11-00038.1

Santos JA, Woollings T, Pinto JG (2013) Are the winters 2010 and 2012 archetypes exhibiting extreme opposite behavior of the North Atlantic jet stream? Mon Weather Rev 141:3626-3640. doi:10.1175/MWR-D-13-00024.1

Seager R, Kushnir Y, Nakamura J, Ting M, Naik N (2010) Northern Hemisphere winter snow anomalies: ENSO, NAO and the winter 2009/10. Geophys Res Lett 37:L14703. doi:10.1029/201 0GL043830

Shaw TA, Perlwitz J, Weiner O (2014) Troposphere-stratosphere coupling: links to North Atlantic weather and climate, including their representation in CMIP5 models. J Geophys Res. doi:10.10 02/2013JD021191

Smith KL, Kushner PJ, Cohen J (2011) The role of linear interference in northern annular mode variability associated with Eurasian snow cover extent. J Clim 24:6185-6202. doi:10.1175/ JCLI-D-11-00055.1

Stockdale TN, Anderson DLT, Balmaseda MA, Doblas-Reyes F, Ferranti L, Mogensen K, Palmer TN, Molteni F, Vitart F (2011) ECMWF seasonal forecast system 3 and its prediction of sea surface temperature. Clim Dyn 37:455-471. doi:10.1007/ s00382-010-0947-3

Vitart F, Buizza R, Balmaseda MA, Balsamo G, Bidlot J-R, Bonet A (2008) The new VarEPS-monthly forecasting system: a first step towards seamless prediction. Q J R Meteorol Soc 134(636):1789-1799. doi:10.1002/qj.322

Wang L, Chen W (2010) Downward Arctic Oscillation signal associated with moderate weak stratospheric polar vortex and the cold December 2009. Geophys Res Lett 37:L09707. doi:10.1029/201 0GL042659 